\title{
The influence of non-linear frequency compression on the perception of music by adults with a moderate to severe hearing loss: Subjective impressions
}

\author{
M Uys, L Pottas, B Vinck, C van Dijk \\ Department of Communication Pathology, University of Pretoria \\ Marinda Uys \\ Lidia Pottas \\ Bart Vinck
}

Ear Institute, Queenswood, Pretoria, South Africa, and Department of Communication Pathology, University of Pretoria

Catherine van Dijk

Corresponding author: M Uys (marinda.uys@gmail.com)

\begin{abstract}
Objective. To date, the main direction in frequency-lowering hearing aid studies has been in relation to speech perception abilities. With improvements in hearing aid technology, interest in musical perception as a dimension that could improve hearing aid users' quality of life has grown. The purpose of this study was to determine the influence of non-linear frequency compression (NFC) on hearing aid users' subjective impressions of listening to music.

Design \& sample. A survey research design was implemented to elicit participants' $(N=40)$ subjective impressions of musical stimuli with and without NFC.

Results. The use of NFC significantly improved hearing aid users' perception of the musical qualities of overall fidelity, tinniness and reverberance. Although participants preferred to listen to the loudness, fullness, crispness, naturalness and pleasantness of music with the use of NFC, these benefits were not significant.

Conclusion. The use of NFC can increase hearing aid users' enjoyment and appreciation of music. Given that a relatively large percentage of hearing aid users express a loss of enjoyment of music, audiologists should not ignore the possible benefits of NFC, especially if one takes into account that previous research indicates speech perception benefits with this technology.
\end{abstract}

Keywords: Hearing loss, music perception, non-linear frequency compression, hearing aids, cochlear dead regions, subjective impression

S Afr J CD 2012;59(1):53-67. DOI:10.7196/SAJCD.119

High-frequency hearing loss is by far the most common audiometric configuration found in individuals fitted with hearing aids (Nyffeler, 2008) and may adversely affect speech comprehension as well as the ability to detect and identify music and lyrics (Glista \& McDermott, 2008). High-frequency hearing loss therefore excludes many people from the daily exposure to music, an integral part of life encountered on numerous occasions each day. Not being able to hear music is problematic as music enhances the quality of a person's life and serves as a medium that models social structures, facilitates the acquisition of social competence by young people and provides human interaction (Cross, 2006).

In attempting to improve music as well as speech perception, a common clinical practice in fitting hearing aids to individuals with high-frequency hearing loss is to provide additional amplification in the higher frequencies (Munro, 2007). Providing this additional high-frequency amplification is often problematic, since some people may unknowingly present with cochlear dead regions and perceive high-frequency amplification as distorted or noise-like in quality. Individuals with cochlear dead regions may have different frequencygain requirements than those without dead regions; the diagnosis of the presence of dead regions may have important clinical implications for benefit from amplification, counselling and hearing aid selection (Munro, 2007).

Many researchers have suggested the possibility of frequency lowering as a means of making speech sounds audible for patients with dead regions (Bagatto, Scollie, Glista, Parsa \& Seewald, 2008; Moore, 2001). These suggestions resulted in various research projects being conducted with frequency-lowering hearing aids in which the emphasis was placed on improved speech perception (Bagatto et al., 2008; Scollie, Glista, Bagatto \& Seewald, 2011). Although research on frequency-lowering hearing aids and music perception is limited, a previous study reported that non-linear frequency compression (NFC) significantly improved hearing aid users' perception of timbre and melody (Uys, Pottas, van Dijk \& Vinck, 2012) and therefore warrants further investigations with this technology to assist music-loving hearing aid users.

There has been an increase in people with hearing loss expressing an equal need for their hearing aids to be fitted optimally for listening to music and speech (Chasin, 2003). This escalating interest in musical perception accuracy and enjoyment is also reflected in publications of a variety of investigations utilising different experiments to assess performance on musical tasks (Uys \& Van Dijk, 2011; Cooper, Tobey \& Loizou, 2008; Gfeller et al., 2002; Looi, McDermott, McKay \& Hickson, 2008; Nimmons et al., 2008).

Because of the complex nature of music, amplification of musical stimuli poses a challenge to audiologists and listening to music may give rise to a large variety of experiences that are based on interrelated emotional and cognitive processes in the brain (Kreutz, Schubert \& Mitchell, 2008). For example, one individual's deepest appreciation of music may be based on the structural features of a musical work, whereas for another the emotional content of a musical piece may elicit strong experiences. Music processing probably depends on cognitive styles that vary between individuals, as well as numerous participative factors that influence enjoyment including personal preferences for musical genres, the situational context such as the listening environment and the listener's mood (Nimmons et al., 2008). These factors may all greatly affect music perception and render it difficult to measure.

The effects of hearing aid processing on musical signals and the perception of music have received very little attention in research (Hockley, Bahlmann \& Chasin, 2010; Wessel, Fitz, Battenberg, 
Schmeder \& Edwards, 2007) although listeners with a hearing loss are no less interested in music than normal-hearing listeners. Every person is immersed in an environment filled with sound, and being able to understand speech is not the only function of hearing. For most people, listening to music is also a significant and enjoyable experience. Therefore, it is not surprising that people with hearing aids frequently express a wish to be able to enjoy listening to music with their device instead of having to remove it when listening to music because of the reduced sound quality provided by the amplification device (Wessel et al., 2007).

The field of audiology acknowledges the value of musical perception in quality of life. The benefits of music, as well as music therapy, in the physiological, psychological and social-emotional aspects of a person's life have been stressed. Therefore a modification of the output of conventional hearing aids in the form of NFC should be investigated as this technology might improve the music perception abilities of some adults with a hearing loss. This article focuses on how participants perceive the loudness, fullness, crispness, naturalness, overall fidelity, tinniness, reverberance and pleasantness of music when listened to with and without NFC. These musical qualities are defined as:

- Loudness - the music is sufficiently loud, as opposed to soft or faint.

- Fullness - the music is full, as opposed to thin.

- Crispness - the music is clear and distinct, as opposed to blurred and diffuse.

- Naturalness - the music seems to be as if there is no hearing aid and as I remember it.

- Overall fidelity - the dynamics and range of the music are not constrained or narrow.

- Tinniness - hearing the quality of tin or metal, a sense of cheap, low-quality sound.

- Reverberance - the persistence of sound after the original sound is removed, a series of echoes.

- Pleasantness - a feeling of enjoyment or satisfaction, as opposed to an annoying or irritating feeling.

\section{Method}

\section{Aim}

The aim was to determine the influence of NFC on participants' subjective impression of listening to music.

\section{Study design}

A survey research design was implemented and participants were asked to complete two short questionnaires. The first questionnaire obtained background information from participants while the second questionnaire elicited a subjective impression of participants' musical experiences with hearing aids when NFC was both active and inactive. Single blinding was used to remove any potential participant bias that could influence results as participants did not know whether the NFC algorithm was activated or not during the evaluation.

\section{Ethical aspects}

Ethical clearance for this study was obtained from the institutions involved. As the underlying foundation of ethical research is to preserve and protect the human dignity and rights of all the participants, the ethical principles of autonomy, beneficence, non-maleficence and justice were adhered to (Leedy \& Ormrod, 2005).

\section{Participants}

A purposive convenience sampling method was implemented where participants were chosen on the basis of accessibility and because they articulated with the aims of the study. The hearing aid users $(N=40)$ met the following criteria:

- Bilateral, moderate to severe sensory neural hearing loss, with a pure tone average of $41-90 \mathrm{~dB}$ at the frequencies $500 \mathrm{~Hz}, 1000$ $\mathrm{Hz}$ and $2000 \mathrm{~Hz}$.

- Normal middle-ear functioning.

- Participants had to be between the ages of 18 years 0 months and 64 years 11 months. This ensured that participants had matured central auditory systems (as the maturation of the central auditory nerve system is completed at the age of approximately 12 years (Bellis, 2003)) and participants were legally independent.

- Participants should not have had NFC hearing aids before and their current hearing aids had to be digital as opposed to analogue. Previous experience with NFC technology would possibly have influenced the participant's beliefs and attitudes towards frequency-lowering technology and therefore could have caused the participant not to be objective in the study; with the current use of analogue hearing aids one might measure the switch from analogue to digital and not the effects of NFC (Flynn, Davis $\&$ Pogash, 2004). The hearing aids used in this study were digital hearing aids; for participants already used to digital amplification, it might reduce adaptation problems and time to adjust to the new hearing aids.

- English language proficiency and literacy. This is a language in which the researcher is proficient and therefore the questionnaires, all instructions and explanations were provided in English. Furthermore, the 2001 South African Census indicated that English is the third most common primary language, the most common second language in Gauteng and the most commonly used language in South Africa (Napier \& Napier, 2002).

- No minimal musical background or experience level was required.

Table 1 provides the biographical information of participants while Table 2 provides an overview on participants' musical background.

The average age of participants was 57.7 years (range 18 - 64 years) and all of them had postlingual onset of hearing loss.

\section{Material and apparatus}

Self-compiled questionnaires (Appendices A and B) were used to obtain background information from participants as well as information on their subjective impression of music with NFC.

Questionnaire 1: This questionnaire aimed at obtaining information regarding the participants' musical background as this might influence the results of the study and assist in the interpretation of the obtained results. Table 3 provides a presumption and literature reference of all the questions included in this questionnaire.

Questionnaire 2: The second questionnaire was in the form of a selfreport questionnaire. The questions were revised from the Munich Music Questionnaire (Medel Medical Electronics, 2006) used to evaluate the listening habits of people with postlingual deafness after cochlear implantation and a five-point perceptual scale used by Chasin (2003) to obtain measures of sound quality. This five-point scale used is a modification of the work of Gabrielsson and colleagues and has been used extensively in the hearing aid industry (Chasin, 2003).

The prototype hearing aids used were Phonak Naida III Ultra Power behind-the-ear hearing aids. These hearing aids are digital and provide non-linear amplification in the form of multiband compression. They were selected because they make use of the NFC algorithm investigated and were available as loan devices from the manufacturer.

\section{Reliability and validity}

To obtain reliability to the highest possible degree the following steps were implemented (Leedy \& Ormrod, 2005):

- Each participant was contacted personally, telephonically or by e-mail to explain the purpose of the study and to obtain their consent to participate.

- A qualified audiologist performed all test procedures and real-ear measurements.

- Questions in the questionnaires were formulated in such a way as to eliminate ambiguity and to ensure clear and precise wording and instructions.

To ensure validity, the following steps were taken (Leedy \& Ormrod, 2005): 


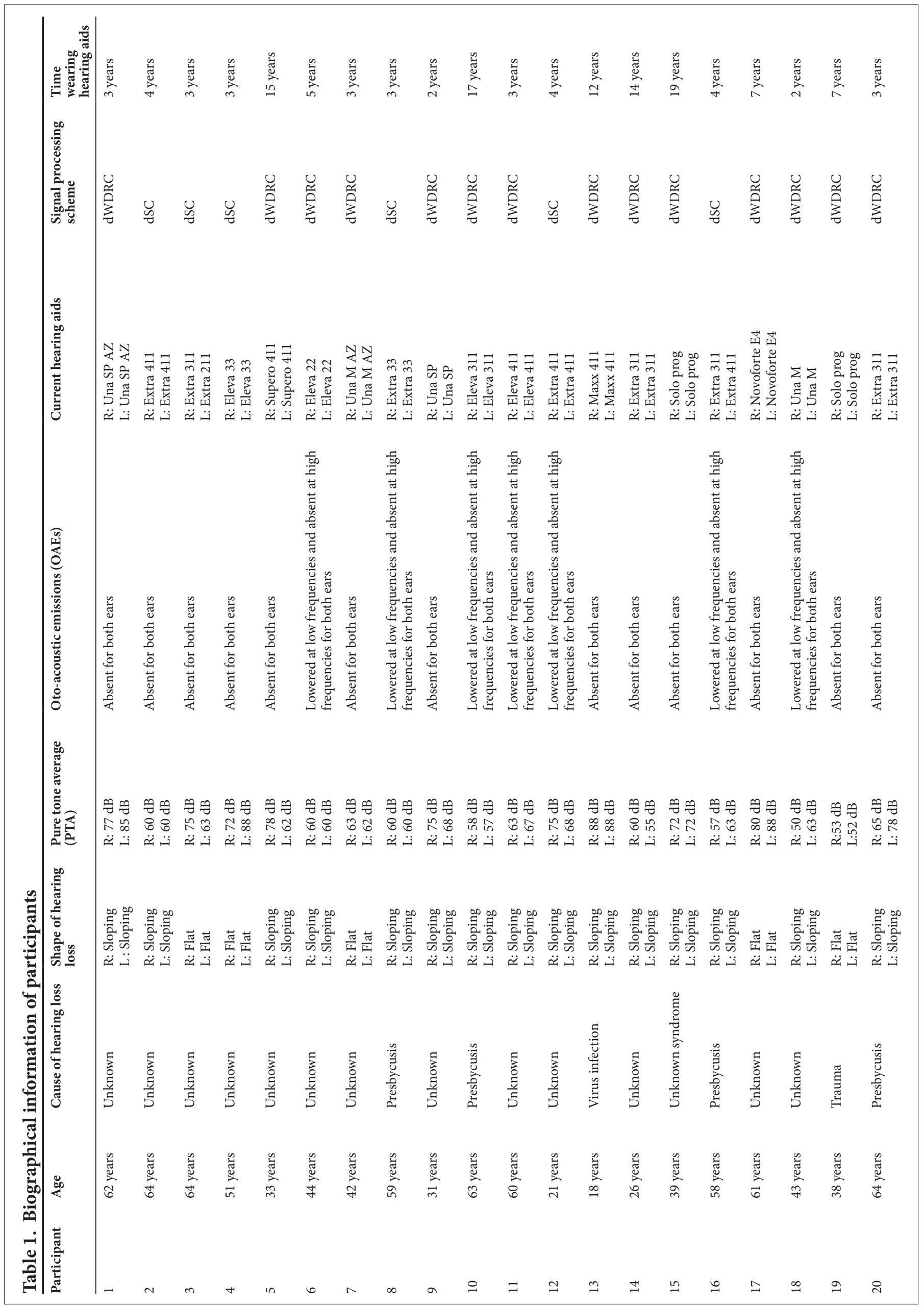




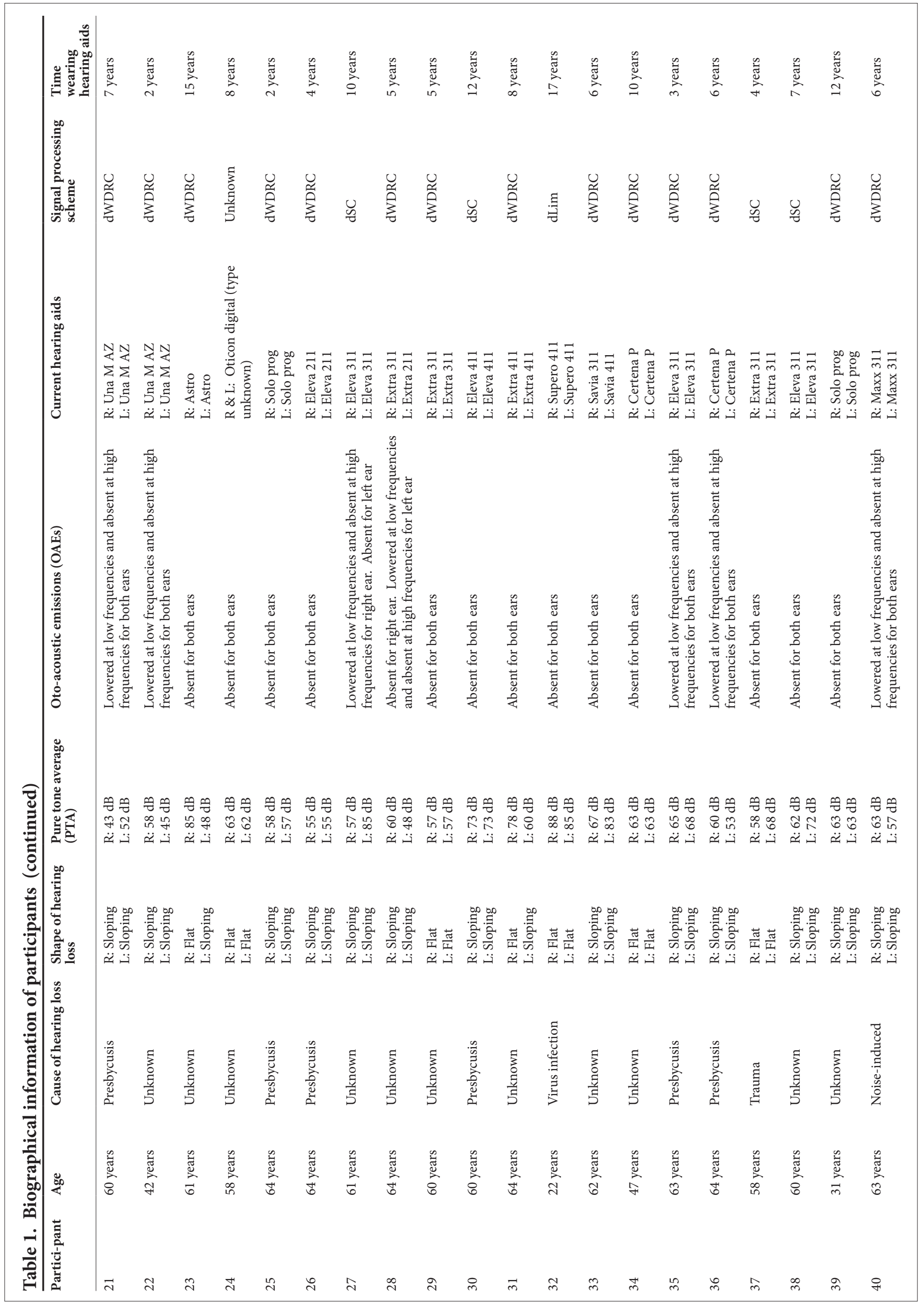


Table 2. Participants' musical history

\begin{tabular}{|c|c|c|c|c|c|c|}
\hline Participant & $\begin{array}{l}\text { Musical training } \\
\text { received }\end{array}$ & $\begin{array}{l}\text { Formal musical } \\
\text { qualification }\end{array}$ & $\begin{array}{l}\text { Musical instruments } \\
\text { currently playing/ } \\
\text { played before }\end{array}$ & $\begin{array}{l}\text { Currently sing or ever have } \\
\text { sung in a choir or at social/ } \\
\text { professional gatherings }\end{array}$ & $\begin{array}{l}\text { Feel that enjoyment of } \\
\text { music has decreased with } \\
\text { hearing problems }\end{array}$ & $\begin{array}{l}\text { Remove hearing } \\
\text { aid when listening } \\
\text { to music }\end{array}$ \\
\hline 1 & 2 years & - & - & No & No & No \\
\hline 2 & - & - & - & No & Yes & No \\
\hline 3 & 2 years & - & Piano & No & No & No \\
\hline 4 & - & - & Guitar, piano & Yes & Yes & No \\
\hline 5 & - & - & - & No & No & Yes \\
\hline 6 & - & - & - & No & Yes & No \\
\hline 7 & - & - & - & Yes & No & Yes \\
\hline 8 & 5 years & Unisa grade 3 & Piano & No & Yes & No \\
\hline 9 & - & - & - & Yes & Yes & No \\
\hline 10 & - & - & - & Yes & Yes & No \\
\hline 11 & 7 years & Unisa grade 8 & Piano & Yes & Yes & No \\
\hline 12 & - & - & Trumpet & Yes & No & No \\
\hline 13 & - & - & - & No & Yes & No \\
\hline 14 & - & - & - & Yes & Yes & No \\
\hline 15 & 20 years & - & Piano & Yes & No & No \\
\hline 16 & 5 years & - & Piano & Yes & Yes & No \\
\hline 17 & - & - & - & No & No & No \\
\hline 18 & 6 years & - & Flute, keyboard, guitar & Yes & No & Yes \\
\hline 19 & 14 years & Unisa grade 6 & Piano & Yes & Yes & Yes \\
\hline 20 & - & - & - & Yes & Yes & No \\
\hline 21 & 6 years & Unisa grade 5 & Piano, violin & Yes & Yes & No \\
\hline 22 & - & - & - & No & Yes & No \\
\hline 23 & - & - & - & No & No & No \\
\hline 24 & - & - & - & Yes & Yes & No \\
\hline 25 & - & - & - & Yes & No & No \\
\hline 26 & 2 years & - & Piano & Yes & Yes & Yes \\
\hline 27 & - & - & - & Yes & Yes & No \\
\hline 28 & 20 years & Unisa grade 8 & Piano & No & No & No \\
\hline 29 & - & - & Piano & Yes & No & No \\
\hline 30 & 1 year & - & Violin & No & Yes & No \\
\hline 31 & 1 year & - & Piano, harmonica & Yes & No & No \\
\hline 32 & - & - & - & Yes & No & Yes \\
\hline 33 & 3 years & Unisa grade 4 & Piano & No & Yes & No \\
\hline 34 & - & - & - & Yes & Yes & Yes \\
\hline 35 & 10 years & - & $\begin{array}{l}\text { Guitar, piano, } \\
\text { harmonica }\end{array}$ & Yes & Yes & Yes \\
\hline 36 & 2 years & - & Accordion & No & Yes & No \\
\hline 37 & - & - & - & No & Yes & No \\
\hline 38 & - & - & - & No & Yes & No \\
\hline 39 & - & - & Piano & Yes & No & No \\
\hline 40 & - & - & - & Yes & No & No \\
\hline
\end{tabular}

- The aims of the study were clearly and precisely formulated.

- A literature study was conducted to ensure that the questions included in the questionnaires were relevant to the validation of the hearing aid fitting process and music perception.

- The researcher included many participants in this study. The validity of a study increases with an increase in sample size.

- Biographical data were obtained from each participant to account for the possibility of a person's musicality having an influence on the results.
Furthermore, the use of relevant literature and discussions with professionals in the music industry concerning the design of the questionnaires ensured that content validity was obtained. To ensure construct validity, the researcher tried to keep all instructions, language use and the format of the questionnaires as simple as possible and avoided ambiguous as well as biased questions. Because of the lack of existing evaluation material for this study, the questionnaires used in this study could not be compared to other questionnaires and therefore criterion validity could not be obtained. 


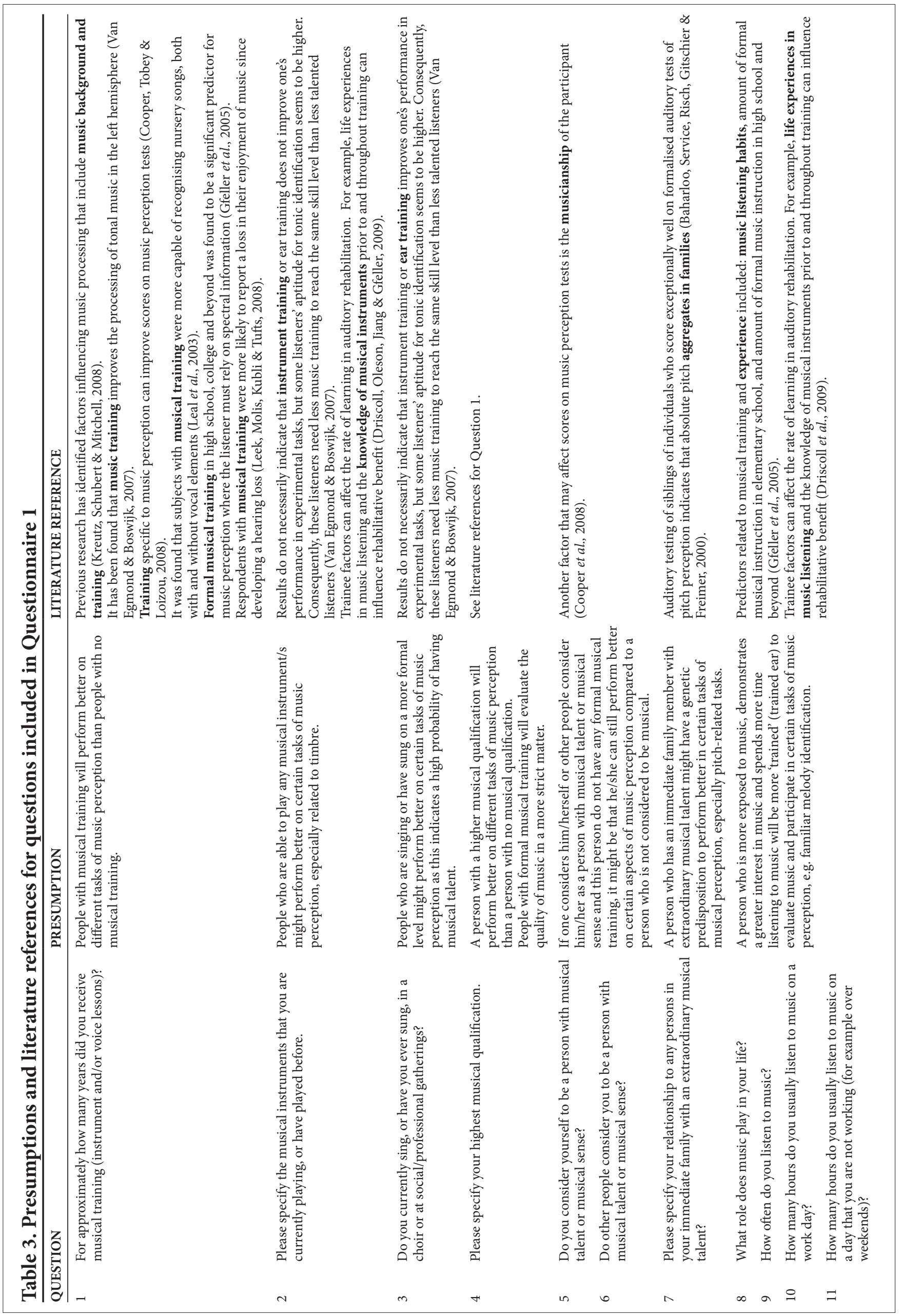




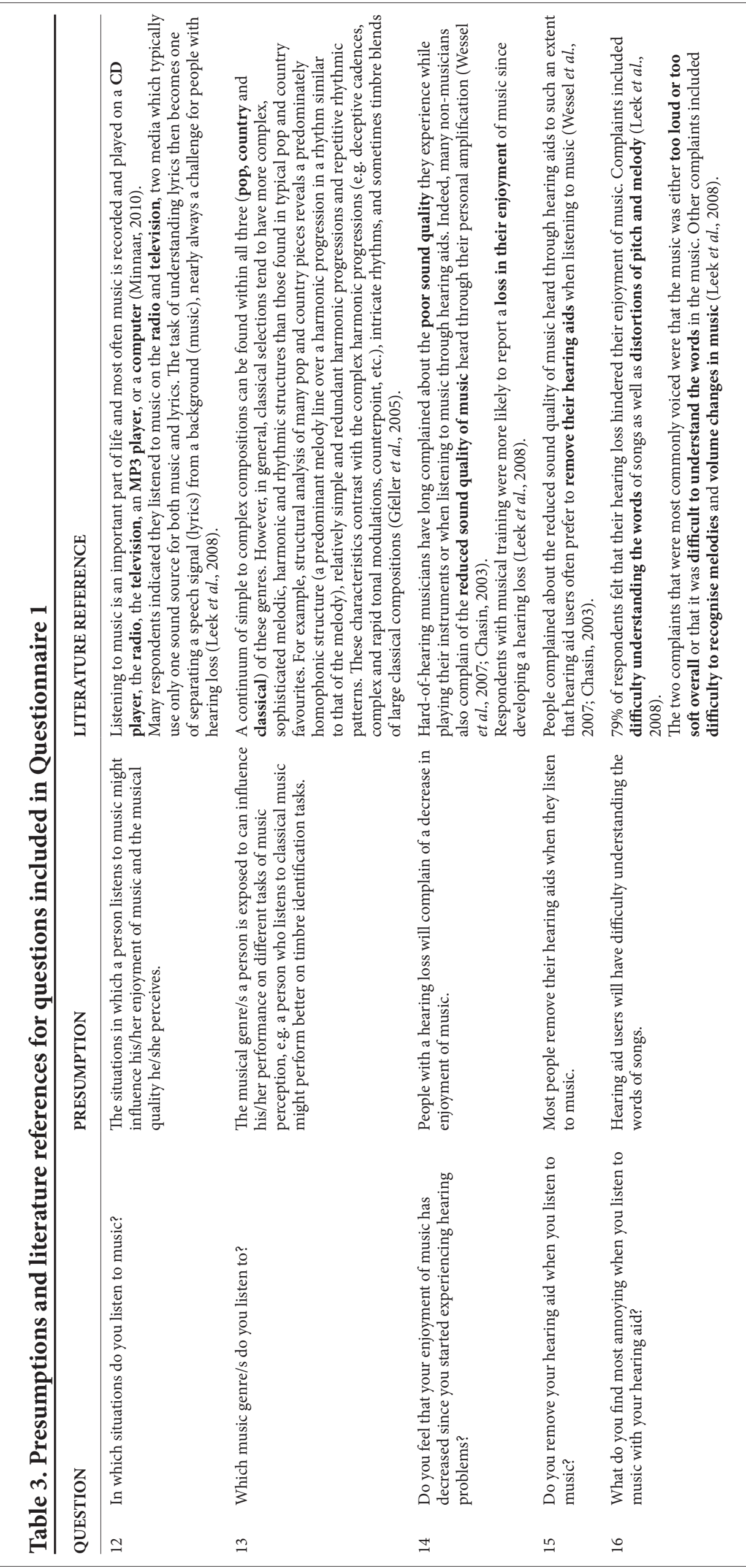

\section{Procedure}

In order for the researcher to obtain subjective data, participants visited the practice three times. During their first visit participants underwent a hearing evaluation to determine candidacy. This included otoscopic examination, immittance testing, oto-acoustic emissions, pure tone and speech audiometry. Participants' current hearing aids were verified with real-ear measurements to ensure that they were optimised to reflect current best practice (Flynn et al., 2004) and to ensure that positive changes could be contributed to NFC and not to optimisation of the current hearing aids. In the case where a participant's current hearing aids were not well fitted, extra time was provided to adjust to the optimised fitting without NFC and the study commenced for these participants after an acclimatisation period of 3 weeks.

Participants were then divided into 4 groups of 10 persons each. A randomised schedule was implemented in order for half of the participants to start with NFC active and the other half with the algorithm inactive. The prototype hearing aids were fitted with the Audioscan Verifit to accurately match the prescribed DSL v5.0 targets for adults. The DSL fitting prescription was chosen over the NAL-NL1 fitting prescription because DSL prescribes more overall gain than NALNL1 for all hearing losses and provides more high-frequency emphasis than NAL-NL1 for sloping and severe losses (Scollie, 2006). All automatic sound features such as noise reduction and adaptive directionality were turned off to prevent these systems from interpreting the music as noise or feedback, which may affect the sound quality that participants perceive (Hockley et al., 2010). Fine tuning adjustments were made according to participants' preferences by adjusting the cut-off frequency (determines the start of the upper band of NFC) and the compression ratio (determines the amount of frequency compression applied to the upper band) of the NFC algorithm. The cut-off frequency and compression ratio were determined on an individual basis using the Phonak fitting software suggestions (Bagatto et al., 2008). Default settings were only changed if participants had complaints about the sound quality. Participants were asked to complete the questionnaire that provides background information and wear the hearing aids for 4 weeks after which they returned to the practice. Previous NFC research indicated that benefits are best achieved with an acclimatisation period of at least 4 weeks (Nyffeler, 2008).

Participants' second visit started with the electro-acoustical verification of the prototype hearing aids to ensure that they were working properly (Flynn et al., 2004). They were then asked to complete the second questionnaire and give feedback on how they experienced listening to music during the 4 weeks that 
they wore the NFC hearing aids. Participants were asked to hand in the completed questionnaire before leaving the practice. At the end of the session the hearing aid settings were switched - participants who had their hearing aids with NFC active now had this algorithm deactivated and vice versa.

During participants' third visit to the practice the hearing aids were once again verified electro-acoustically. Participants were again asked to complete the second questionnaire and reflect on their musical listening experiences during the past 4 weeks. Again the completed questionnaires were handed in at the end of the session. Results obtained with NFC active and inactive were evaluated and compared for each participant.

\section{Data recording}

Every questionnaire received a respondent number to ensure participants' anonymity, ranging from 01 to 40 for each completed group of questionnaires (Questionnaire 1, Questionnaire 2 after second visit and Questionnaire 2 after third visit). All questionnaires were checked to ensure that they were completed in full. A coding system was used for recording the responses to the questions and a code was created for every possible answer. In the case of 'Yes/No' questions, the code 1 was assigned to the answer 'Yes' and code 0 to 'No'. Where there were various answers to a question, a code was allocated to each answer, for example codes 1 to 5 for each of the possible five answers. This method facilitated statistical analysis of the results.

\section{Data analysis}

Descriptive statistics were used during this study to classify, organise and summarise the observations in a manner convenient for numerically evaluating the attributes of the available data (McMillan \& Schumacher, 2006). Statisticians were consulted throughout the course of the study and a combination of statistical software packages such as Excel and the Statistical Package for the Social Sciences (SPSS) were used. Results were converted to percentages and were described in terms of percentages. In order to determine whether the application of NFC resulted in significant benefits for the different musical qualities, the Wilcoxon matched-pairs signed rank test was used. This test is appropriate for studies involving repeated measures in which the same subjects serve as their own control (Maxwell \& Satake, 2006). It was therefore applicable to the results obtained from the second questionnaire because this questionnaire was non-parametric owing to the ranking scale used. Participants had to complete the questionnaire twice as they were asked to give their impression on the different musical qualities with and without NFC. Analysed data were visually presented in the form of graphs.

\section{Results}

As the musical genres that people listen to can influence their perception of the quality of music, participants were asked to indicate which musical genres they prefer. These preferences are displayed in Figure 1.

Most of the participants prefer to listen to folk/country music (67.5\%) followed by classical music (62.5\%). Folk/country music often focuses on stories of everyday life with lyrics being a key aspect of this musical genre while classical music can be categorised into broad styles with distinct structural features (e.g. Baroque music, classical music, romantic music) and tends to have more complex, sophisticated melodic, harmonic and rhythmic structures than those found in other musical genres (Gfeller et al., 2005). The musical genres least preferred by participants were rock music (17.5\%) and jazz/blues (12.5\%).

Participants were then asked to complete the rating scale included in Questionnaire 2 which assessed the musical qualities of loudness, fullness, crispness, naturalness, overall fidelity, pleasantness, tinniness and reverberance. Whereas a higher score for the adjectives loud, full, crisp or clear, natural and pleasant indicates better sound quality, a higher score for the adjectives constrained or narrow, more tinny and echoing generally indicates less desirable sound quality.

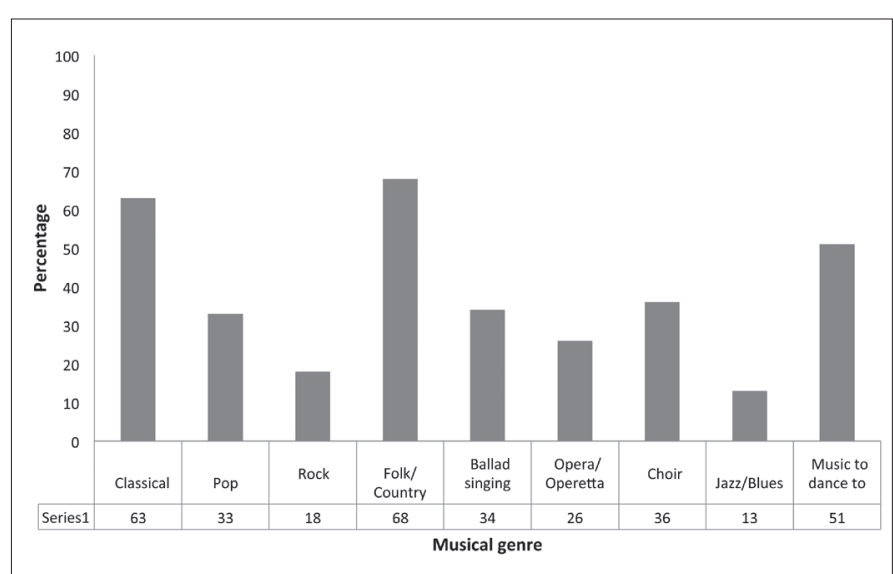

Fig. 1. Participants' musical genre preferences.

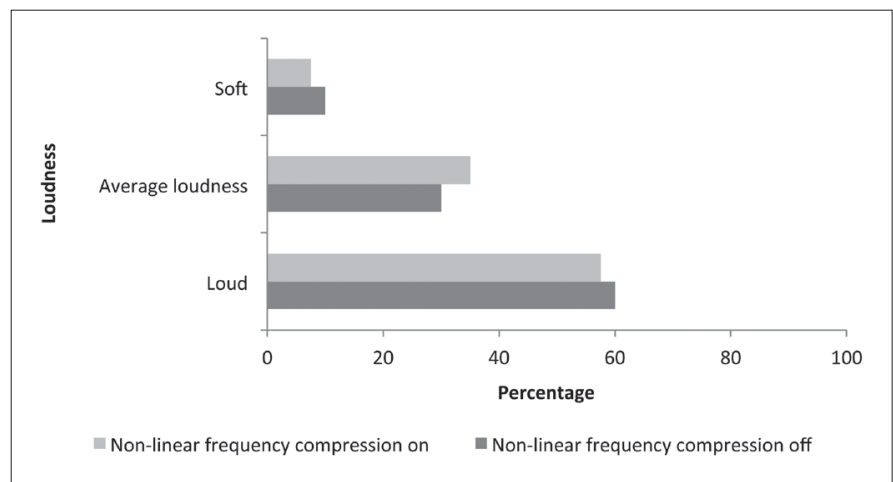

Fig. 2. Participants' perception of musical loudness with NFC off versus NFC on.

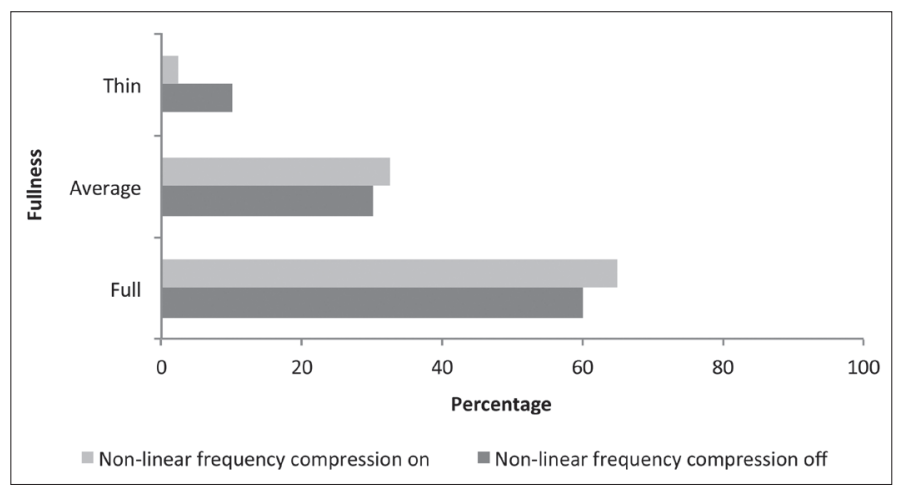

Fig. 3. Participants' perception of the fullness of music with NFC off versus NFC on.

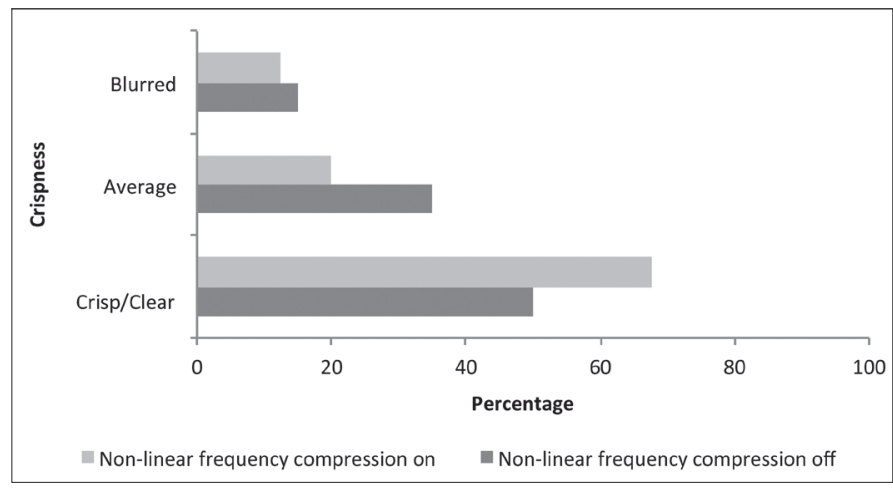

Fig. 4. Participants' perception of the crispness of music with NFC off versus NFC on.

The first musical quality to be assessed was loudness. Participants' perception of the loudness of music is displayed in Figure 2.

Most participants felt that music was sufficiently loud with the hearing aids and there was only a slight difference in the loudness quality 


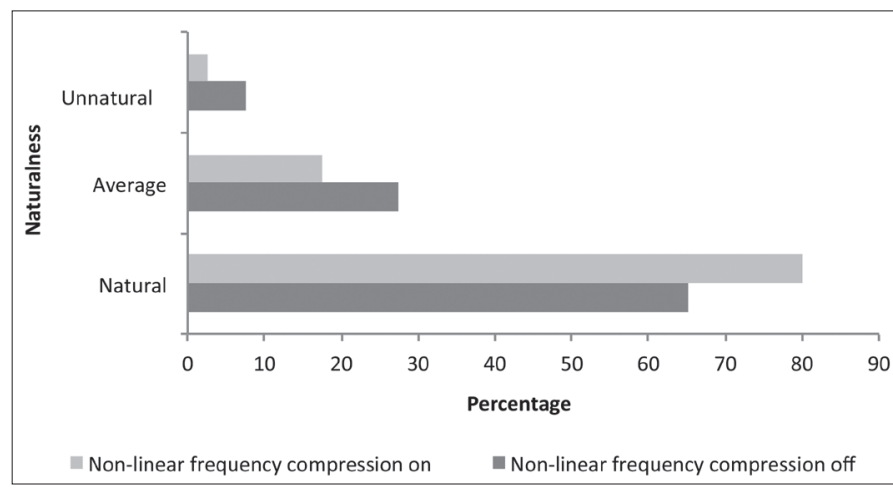

Fig. 5. Participants' perception of the naturalness of music with NFC off versus NFC on.

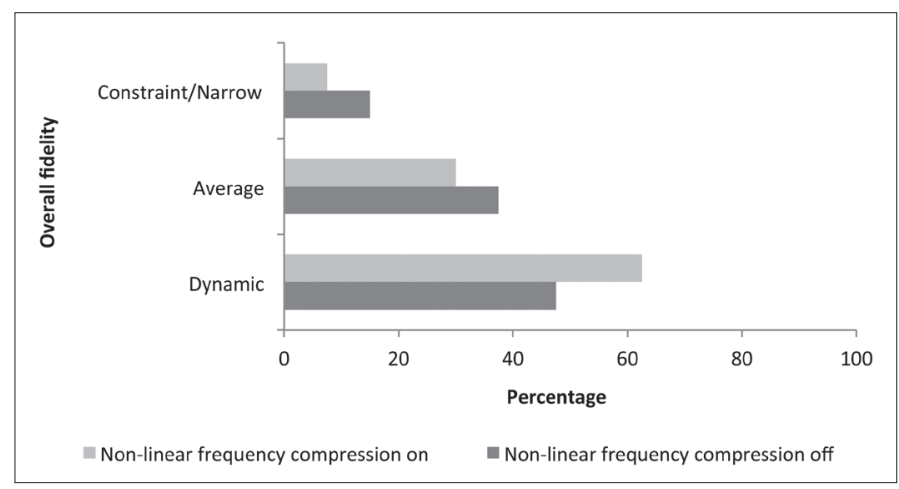

Fig. 6. Participants perception of the overall fidelity of music with NFC off versus NFC on.

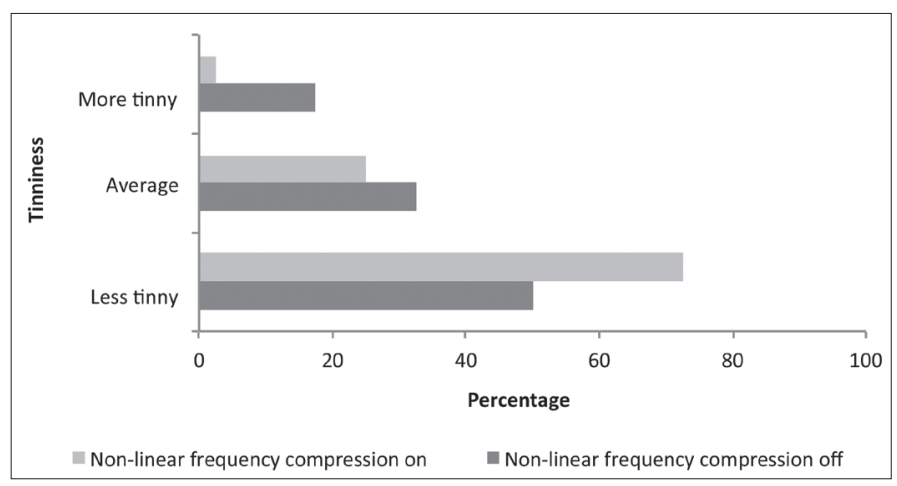

Fig. 7. Participants' perception of the tinniness of music with NFC off versus NFC on.

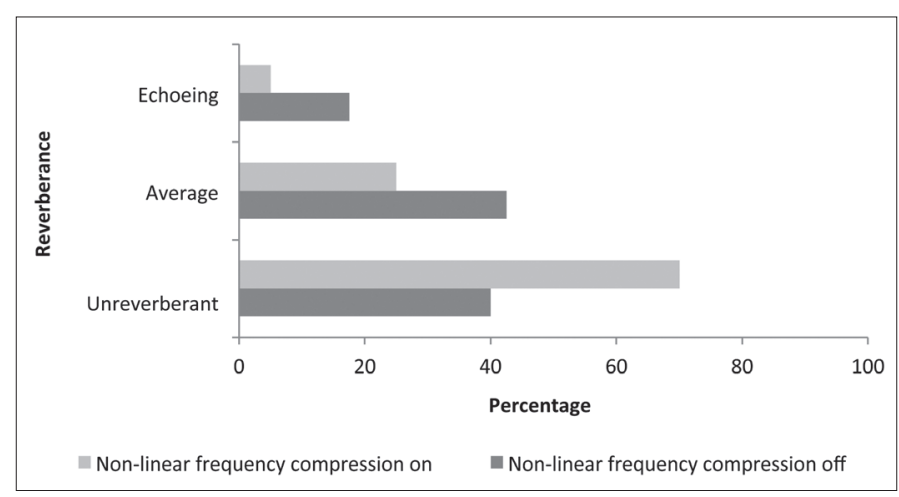

Fig. 8. Participants' perception of the reverberance of music with NFC off versus NFC on.

rating with NFC inactive versus active. As results for the different NFC settings were very similar no significant benefit $(p=0.43)$ was obtained with the activation of this algorithm.

Results for assessment of fullness are displayed in Figure 3.

With NFC active, there was a slight improvement in participants' rating of musical fullness compared with NFC inactive. This improvement was

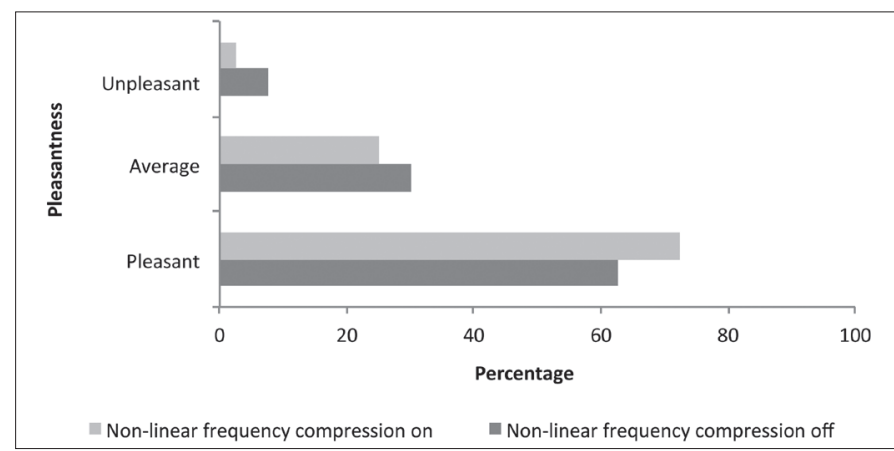

Fig. 9. Participants' perception of the pleasantness of music with NFC off versus NFC on.

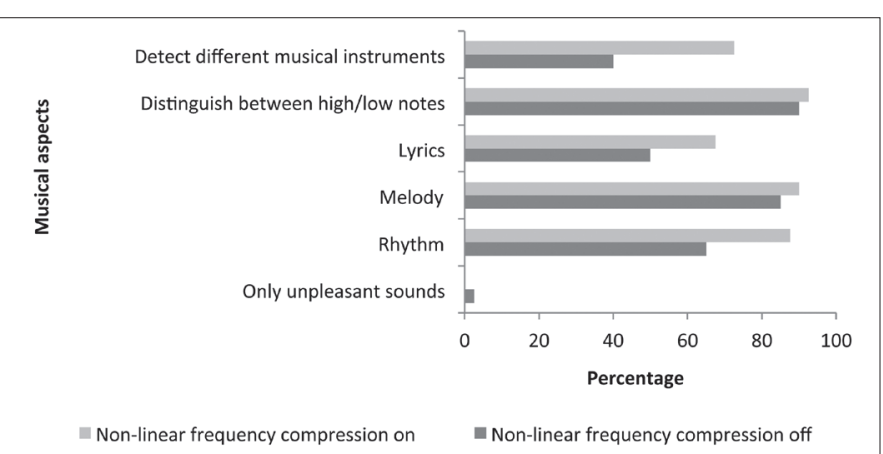

Fig. 10. Participants' ability to discriminate between different musical aspects with NFC off versus NFC on.

however not statistically significant $(p=0.31)$ as $65 \%$ of the participants indicated that the music sounded full as opposed to thin with NFC active compared with $60 \%$ when NFC was inactive.

Musical crispness results are displayed in Figure 4.

When asked about the crispness of music, $67.5 \%$ of the participants concluded that music was clear and distinct with NFC active compared with $50 \%$ with NFC inactive. Again the improved quality experienced with NFC was not significant $(p=0.11)$

Information on the naturalness of music is presented in Figure 5.

Figure 5 displays that $80 \%$ of the participants experienced the quality of music as natural with NFC active compared with $65 \%$ who were satisfied when NFC was inactive. Again it seems that music sounds more natural with the activation of NFC but the benefit was not statistically significant $(p=0.09)$.

Participants' ratings of the overall fidelity of music are presented in Figure 6 .

More participants (62.5\%) described music as sounding dynamic with NFC active, compared with NFC inactive (47.5\%) but the more dynamic quality of music obtained with NFC was however still not statistically significant $(p=0.04)$.

Participants' perceptions of the tinniness of music are displayed in Figure 7.

A statistically significant benefit $(p=0.01)$ with the activation of NFC was obtained with regard to the tinniness of music as most participants found music to sound less tinny with NFC active (72.5\%) compared with it inactive (50\%).

Participants were also asked to rate the musical quality of reverberance (Figure 8).

Again the ratings for NFC active were more positive than those obtained with NFC inactive and resulted in participants experiencing a statistically significant benefit $(p=0.005)$. 
Hearing aid users frequently complain that they have forgone a formerly enjoyable aspect of their lives as they cannot enjoy music to the same extent as before their hearing loss (Leek, Molis, Kubli \& Tufts, 2008). Therefore, hearing aid users in the present study were asked to rate the pleasantness of music (Figure 9).

Overall the pleasantness of music was rated more positively with NFC active than inactive although this benefit was not of statistical significance $(p=0.13)$.

Participants' ability to discriminate between different musical instruments, distinguish between high and low notes, as well as discriminating the lyrics in a song was also assessed. These data are displayed in Figure 10.

While it seems that participants were able to discriminate more positively between different musical qualities with NFC active as opposed to NFC inactive, a statistically significant benefit was only obtained for participants' ability to detect different musical instruments $(p=0.003)$ and discriminate the rhythm $(p=0.015)$ in a musical piece. Although slight benefits with NFC were observed for participants' ability to distinguish between high and low notes $(p=0.18)$, discriminate the lyrics $(p=0.09)$ and melody $(p=0.28)$ in a song, these benefits were not statistically significant.

\section{Discussion}

Studies of music enjoyment by persons with a hearing loss are rare in the literature (Leek et al., 2008) and it is not known how common it is for persons with a hearing loss to find music unpleasant or distorted, or how debilitating and distressing this reaction might be. With regard to the musical qualities assessed in the current study, the following were observed:

Loudness: Most of the participants were satisfied with the loudness of music as the hearing aids used in this study were power hearing aids with an $80 \mathrm{~dB}$ of peak gain and $141 \mathrm{~dB}$ maximum power output (Nyffeler, 2008). Two of the complaints most commonly voiced by hearing aid users are that music is either too loud or too soft overall (Leek et al., 2008). If one takes into consideration that music is louder than speech (Chasin \& Schmidt, 2009) and all participants used the same programme for listening to both music and speech, some participants could easily have experienced the music as being too loud. A possible explanation for their satisfaction with the loudness of music might be that all hearing aids were fitted on target as verified with realear measurements; by doing that the researcher ensured that sounds were not uncomfortably loud. If one considers that the loudness of the sound produced by the hearing aid is determined by the gain and maximum power output of the hearing aid, it is not unexpected that NFC did not have a big influence on loudness.

Fullness: Normal-hearing listeners tend to judge sounds richer in harmonics as fuller whereas cochlear implantees have often described the quality of musical instruments as sounding thinner or shriller compared with how instruments sounded prior to deafness (Gfeller et al., 2002). No research on how hearing aid users described music in terms of fullness could be found with which to compare the results of the current study. Overall, hearing aid users in the present study seemed to be relatively happy with the fullness of music and there was a slight preference towards listening with NFC. The contribution of NFC towards the fullness of music can be explained by the fact that participants hear the high-frequency sounds of music which they previously missed. Although the majority of music pitches exist in the lower half of the auditory spectrum, with corresponding fundamental frequencies at approximately $1000 \mathrm{~Hz}$ and below, the higher frequencies are also important for music (Revit, 2009). Resonances occurring above the fundamental frequency of musical notes help the listener to distinguish the sound of one instrument from another and add harmonicity to the sound. Instrumental harmonic resonance may occur at much higher frequencies than $3000 \mathrm{~Hz}$; for example, the highest notes of a harmonica can have significant harmonics as high as $10000 \mathrm{~Hz}$ (Revit, 2009). Music however is very dynamic and the variety in instrumental timbre (e.g. the more characteristically hollow sound of the clarinet versus the very rich and deep sound of a cello) contributes to the novelty and beauty that listeners seek in music; thus, one sound being judged more empty than another is not inherently undesirable (Gfeller et al., 2002).

Crispness: Hearing aid users often complain of music being blurred and distorted and that melodies are therefore difficult to recognise (Leek $e t$ al., 2008). Normal-hearing listeners have judged sounds having more low-frequency energy as duller or blurred in quality, whereas sounds having more high-frequency energy were judged as sharper (brilliant) or crisper (clear) in quality (Gfeller et al., 2002). With this in mind, it is not unusual that participants rated music as being crisper and clearer with NFC as they were then receiving high-frequency information otherwise missed. The balance between the amounts of high- and lowfrequency amplification should however still be good as hearing aid users do not consistently prefer extended high-frequency responses for listening to music (Wessel et al., 2007).

Naturalness: It is not clear whether people with hearing loss who wear hearing aids can separate the effects of the loss from the alterations in music produced by the hearing aids (Leek et al., 2008) and therefore their definition of naturalness can easily be compared with what they are used to (not hearing all the sounds in music and when presented with more sounds than they are used to, it does not seem natural any more). This is especially possible for persons with a longer onset of hearing loss and persons who have been wearing hearing aids for a longer period of time. No data with regard to the perception of naturalness of music by hearing aid users could be found with which to compare the results of the current study. It is assumed that the naturalness of music will influence participants' perception of the pleasantness of musical stimuli and therefore this aspect should be viewed in conjunction with participants' assessments of pleasantness, which are discussed later.

Overall fidelity: Normal-hearing listeners have rated sounds with more noise as sounding more scattered or narrow (Gfeller et al., 2002) while hearing aid users often complain that some musical instruments sounded odd, as if they could not hear the whole spectrum of an instrument's sound (Chasin, 2003). Results of the present study indicate a definite preference for music being more dynamic with NFC. Again this can be contributed to the high-frequency musical sounds that participants missed without NFC and therefore they are not able to hear the whole spectrum of some musical instruments, e.g. the harmonics of a violin which often exceeds $5000 \mathrm{~Hz}$ (Revit, 2009). Being able to hear the whole spectrum of a different instrument's sound will add to the aesthetic experience of music (Hockley et al., 2010) and therefore one can conclude that the activation of NFC adds to the unique and rich timbral representations of music.

Tinniness: Participants' perception that music sounds less tinny with NFC is actually unexpected if one considers that NFC provides listeners with more high-frequency audibility, and previous research indicated that persons with a hearing loss did not necessarily like a high-frequency emphasis when listening to music (Leek et al., 2008). It is also evident that with frequency compression hearing aids, speech may take on a lisping quality or sounds might have a tinny sound when lowered too much (Scollie et al., 2011). One possible explanation for the indication that music sounds less tinny with NFC might be that the NFC setting for each participant was left on the default setting determined by the hearing aid fitting software and was only adjusted when participants complained about sounds being too tinny or uncomfortable. By doing this the researcher ensured that none of the participants received too much high-frequency amplification and therefore avoided sounds that have a tinny quality.

Reverberance: Perceptions regarding this musical quality are similar to the way participants experience the tinniness of music, as too much high-frequency amplification often causes sounds to have an echo. Again it is unexpected that fewer participants complained about hearing echoes with NFC as they were exposed to more high-frequency 
information. A possible explanation for this phenomenon might be that the researcher ensured that the NFC setting was comfortable for each participant without causing any disturbances in sound quality.

Pleasantness: As music can be very complex and there is no single identity that determines the pleasantness of music (Leal et al., 2003), one can assume that all the musical qualities described above contribute to the way listeners will experience music. From the discussion above it is evident that participants rated the fullness, crispness, naturalness, overall fidelity, tinniness and reverberance of musical stimuli to be more pleasant with NFC and therefore it is not surprising that they rated music to sound more pleasant with NFC. This is important as most people choose to listen to music for personal pleasure and enjoyment (Gfeller et al., 2002).

\section{Conclusion}

One can conclude that participants demonstrated a subjective preference for listening to music with NFC. It is however important to understand that listening to music may give rise to a variety of experiences (Kreutz et al., 2008) and therefore every individual will perceive the same musical stimulus differently. It may be of value to determine the effect of NFC for specific musical instruments in future research. As some musical instruments place more emphasis on highfrequency information compared with others, NFC may be more beneficial to certain musicians, depending on the instrument they are playing.

Given that a relatively large percentage of participants still expressed a loss in enjoyment of music, audiologists should routinely ask patients about their music listening habits and should work with them to provide the best possible amplification options for both speech and music listening. Results obtained from this study can enable audiologists to improve their service to performing musicians and other people who wish music to be part of their lives. Musicians depend on audiologists to enabling them to successfully practise their profession, and music lovers for the improvement of their quality of life. Over the last few years more information regarding music perception with hearing aids and different hearing aid technologies has become available. It is every audiologist's responsibility to continually gain information about new hearing aid technologies as well as fitting preferences and to share this information. If audiologists realise this, they will have reached a new level of success in their profession (Chasin \& Revit, 2009).

This paper has not been presented at any professional meetings.

\section{References}

Bagatto, M., Scollie, S., Glista, D., Parsa, V., \& Seewald, R. (2008). Case study outcomes of hearing impaired listener using nonlinear frequency compression technology. Retrieved from http://www.audiologyonline.com/article detail.asp?article_id $=1990$

Baharloo, S., Service, S.K., Risch, N., Gitschier, J., \& Freimer, N.B. (2000). Familial aggregation of absolute pitch. The American Journal of Human Genetics, 67(3), 755-758. doi:10.1086/303057
Bellis, T. J. (2003). Assessment and management of central auditory processing disorders in the educational setting, from science to practice. San Diego: Singular Group.

Chasin, M., \& Revit, L. J. (2009). Musicians and hearing aid design. Hearing Review, 16(2): 10.

Chasin, M., \& Schmidt, M. (2009). The use of a high frequency emphasis microphone for musicians. Hearing Review 16(2), 32-37.

Chasin, M. (2003). Music and hearing aids. Hearing Journal, 56(7): 36-41.

Cooper, W. B., Tobey, E., \& Loizou, P. C. (2008). Music perception by cochlear implant and normal hearing listeners as measured by the Montreal Battery for Evaluation of Amusia. Ear and Hearing, 29(4), 618-626. doi:10.1097 AUD.0b013e318174e 787

Cross, I. (2006). The origins of music: Some stipulations on theory. Music Perception, 24(1), 79-81.

Driscoll, V. D., Oleson, J., Jiang, D., \& Gfeller, K. (2009). Effects of training on recognition of musical instruments presented through cochlear implant simulations. Journal of the American Academy of Audiology, 20(1), 71-82. doi: $10.3766 /$ jaaa. 20.1 .7

Flynn, M. C., Davis, P. B., \& Pogash, R. (2004). Multiple-channel non-linear power hearing instruments for children with severe hearing impairment: Long-term follow-up. International Journal of Audiology, 3(8), 479-485. doi: 10.1080/14992020400050061

Gfeller, K., Olszewski, C., Rychener, M., Sena, K., Knutson, J. F., Witt, S., \& Macpherson, B. (2005). Recognition of 'real-world' musical excerpts by cochlear implant recipients and normal-hearing adults. Ear and Hearing, 26(3), 237-250. doi:10.1097/00003446-200506000-00001

Gfeller, K., Turner, C., Mehr, M., Woodworth, G., Fearn, R., Knutson, J. F., Witt, S., \& Stordahl, J. (2002). Recognition of familiar melodies by adult cochlear implant recipients and normal-hearing adults. Cochlear Implants International, 3(1), 29-53. doi:10.1002/cii.50

Glista, D., \& McDermott, H. (2008). Phonak SoundRecover: A breakthrough in enhancing intelligibility. Naida Product Information. Switzerland: Phonak Hearing Systems.

Hockley, N. S., Bahlmann, F., \& Chasin, M. (2010). Programming hearing instruments to make live music more enjoyable. Hearing Journal, 63(9), 30-38.

Kreutz, G., Schubert, E., \& Mitchell, L. A. (2008). Cognitive styles of music listening. Music Perception, 26(1), 57-73. doi:10.1525/mp.2008.26.1.57

Leal, M. C., Shin, Y. J. E., Laborde, M. L., Calmels, M., Verges, S., Lugardon, S., Andrieu, S., Deguine, O., \& Fraysse, B. (2003). Music perception in adult cochlear implant recipients. Acta Oto-laryngology, 123, 826-835. doi:10.1080/00016480310000386.

Leedy, P. D., \& Ormrod, J. E. (2005). Practical research. Planning and design (8th ed). Upper Saddle River, NJ: Pearson.

Leek, M. R., Molis, M. R., Kubli, L. R., \& Tufts, J. B. (2008). Enjoyment of music by elderly hearing-impaired listeners. Journal of the American Academy of Audiology, 19(6), 519-526. doi:10.3766/jaaa.19.6.7

Looi, V., McDermott, H., McKay, C., \& Hickson, L. (2008). Music perception of cochlear implant users compared with that of hearing aid users. Ear and Hearing, 29(3), 421-434. doi:10.1097/AUD.0b013e31816a0d0b

Maxwell, D. L., \& Satake, E. (2006). Research and statistical methods in communication sciences and disorders. Scarborough, Ontario: Thomson Delmar Learning.

McMillan, J. H., \& Schumacher, S. (2006). Research in education: Evidence-based inquiry. Washington, DC: Library of Congress Cataloging-in-Publication Data.

Medel Medical Electronics. (2006). Mu.S.I.C Perception Test User Guide. St Asaph: H \& D Fitzgerald Ltd.

Minnaar, P. (2010). Enhancing music with virtual sound sources. The Hearing Journal, 63(9), 38-43.

Moore, B. C. J. (2001). Dead regions in the cochlea: Diagnosis, perceptual consequences, and implications for the fitting of hearing aids. Trends in Amplification, 5(1), 1-34. doi:10.1177/108471380100500102

Munro, K. J. (2007). Integrating cochlear dead region diagnosis into the hearing instrument fitting process. Phonak Focus 38: 1-19. Switzerland.

Napier, D. B., \& Napier, J. D. (2002). Language dominance and hope for language equality in South Africa: Examples from schools. Original paper presented at the Annual Meeting of the Comparative and International Education Society, Orlando. Florida: University of Georgia.

Nimmons, G. L., Kang, R. S., Drennan, W. R., Longnion, J., Ruffin, C., Worman, T., Yueh, B., \& Rubinstein, J. T. (2008). Clinical assessment of music perception in cochlear implant listeners. Otology \& Neurotology, 29(2), 149-155. doi:10.1097/mao.0b013e31812f7244

Nyffeler, M. (2008). Study finds that non-linear frequency compression boosts speech intelligibility. Hearing Journal, $61(12), 22-24$.

Revit, L. J. (2009). What's so special about music? Hearing Review, 16(2), 12-19.

Scollie, S. D., Glista, D., Bagatto, M., \& Seewald, R. (2011). Multichannel nonlinear frequency compression: A new technology for children with hearing loss. Retrieved from https://www.phonakpro.com/content/dam/phonak b2b/pediatrics/webcasts/pediatric/com_24_p61899_pho_kapitel_13.pdf

Scollie, S. (2006). The DSL method: Improving with age. Hearing Journal, 59(9), 10-16.

Uys, M., Pottas, L, van Dijk, C \& Vinck, B. (2012). The influence of non-linear frequency compression on the perception of music by adults with a moderate to severe hearing loss: Test results. South African Journal of Communication Disorders (in review).

Uys, M., \& van Dijk, C. (2011). Development of a music perception test for adult hearing aid users. South African Journal of Communication Disorders, 58(1), 19-47.

Van Egmond, R., \& Boswijk, M. (2007). The perception of key: The role of music training. Music Perception, 25(1), $31-42$.

Wessel, D., Fitz, K., Battenberg, E., Schmeder, A., \& Edwards, B. (2007). Optimizing hearing aids for music listening. Retrieved from http://cnmat.berkeley.edu/publication/optimizing_hearing_aids_music_listening. 


\section{Appendix A.}

\section{THE INFLUENCE OF NON-LINEAR FREQUENCY COMPRESSION ON MUSIC PERCEPTION}

QUESTIONNAIRE 1: BACKGROUND INFORMATION
For office use only
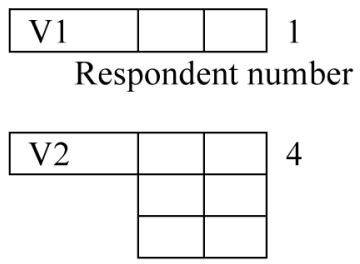

Pt Date of birth

Please read the following questions carefully and answer them by placing a written response in the space provided or tick in the appropriate column/columns. Should you wish to add any comments, space has been provided at the end of the questionnaire. Please do not leave any question unanswered.

1. For approximately how many years did you receive musical training (instrument and/or voice lessons)?

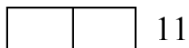

2. Please specify the musical instruments that you are currently playing, or have played before:

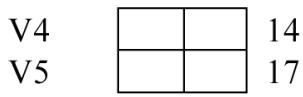

3. Do you currently sing, or have you ever sung, in a choir or at social/professional gatherings?

YES

NO

V6

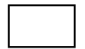

20

4. Please specify your highest musical qualification:

5. Do you consider yourself to be a person with musical talent or musical sense?

\section{YES}

NO

V8

6. Do other people consider you to be a person with musical talent or musical sense?

\section{YES}

NO

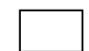

V9 27

7. Please specify the relationship to you of any persons in your immediate family with an extraordinary musical talent?

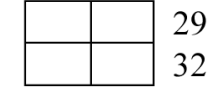

8. What role does music play in your life? Please circle the applicable answer.
A big role $\underline{5}$ 4 3 2

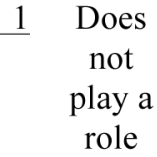

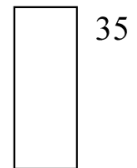


9. How often do you listen to music? Please circle the applicable answer.
A lot
$\underline{5}$
4
3
2
1 Never
V13 37

10. How many hours do you usually listen to music on a work day?

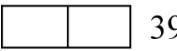

11. How many hours do you usually listen to music on a day that you are not working (for example over weekends)?

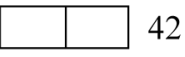

12. In which situations do you listen to music? Please tick all the applicable answers.

Over the television

On the computer

At social events

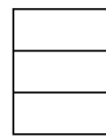

At formal music events

On the radio in the car

$\mathrm{Hi}$-fi/Ipod/MP3
V16

V18

V20

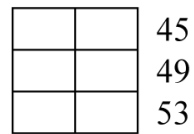
49 53

13. Which musical genre(s) do you listen to?

Classical music
Pop music
Rock music
Folk/Country music
Ballad singing

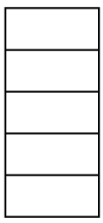
Opera/Operetta Choir music Jazz/Blues

Music to dance to
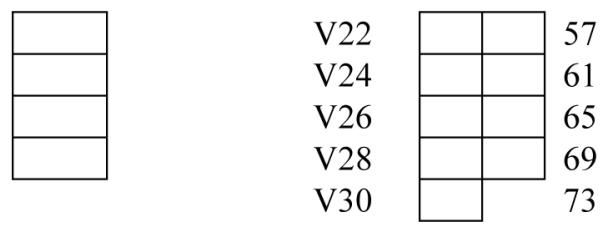

14. Do you feel that your enjoyment of music has decreased since you started experiencing hearing problems?

YES

NO

15. Do you usually remove your hearing aid when you listen to music?

YES

NO

16. What do you find most annoying when you listen to music with your hearing aid?

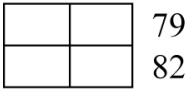

17. Please state any additional comments you may have regarding this subject.

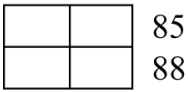

PLEASE READ THROUGH THE QUESTIONNAIRE TO ENSURE THAT ALL THE QUESTIONS WERE ANSWERED.

THANK YOU FOR YOUR CO-OPERATION 
Appendix B.

\section{THE INFLUENCE OF NON-LINEAR FREQUENCY COMPRESSION ON MUSIC PERCEPTION}

QUESTIONNAIRE 2: IMPRESSION OF MUSIC PERCEPTION
For office use only

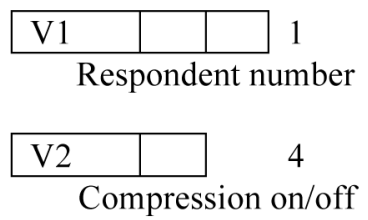

Please read the following questions carefully and answer them by placing a written response in the space provided or tick in the appropriate column/columns. Should you wish to add any comments, space has been provided at the end of the questionnaire. Please do not leave any question unanswered.

The following questions are regarding your musical experience with the hearing aids as used during the last 4 weeks.

1. To which musical genre do you listen to mostly (your favorite musical genre)?

$$
\begin{gathered}
\text { Classical music } \\
\text { Pop music } \\
\text { Rock music } \\
\text { Folk/Country music } \\
\text { Ballad singing }
\end{gathered}
$$

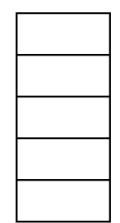

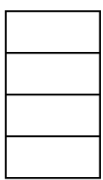

Music to dance to

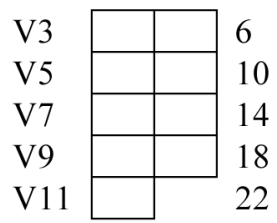

2. How does listening to your favorite musical genre generally sound with the hearing aid? Please circle the applicable answer.

2.1 Loudness: The music is sufficiently loud, as opposed to soft or faint.

Loud 4 3 2 Soft

2.2 Fullness: The music is full, as opposed to thin.

Full 5 4 3 2 1

Thin

2.3 Crispness: The music is clear and distinct, as opposed to blurred and diffuse.

Crisp/ $\underline{5}$ $4 \quad 3$ 32 1 $1 \quad$ Blurred

Clear

2.4 Naturalness: The music seems to be as if there is no hearing aid, and the music seems as 'I remember it'.

Natural 4 3 2 1 Unnatural

2.5 Overall fidelity: The dynamics and range of the music is not constrained or narrow.

Dynamic 4 3 2 1 Constrained Narrow

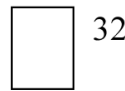

2.6 Pleasantness: A feeling of enjoyment or satisfaction, as opposed to annoying or irritating.

Pleasant 4 3 2 1 Unpleasant

2.7 Tinniness: Hearing the quality of tin or metal, a sense of a cheap, low-quality sound.

Less tinny $\underline{5}$

4 3 2 1 More tinny 
2.8 Reverberant: The persistence of sound after the original sound is removed, a series of echoes.

\begin{tabular}{lllllllll}
$\begin{array}{l}\text { Un- } \\
\text { reverberant }\end{array}$ & 5 & 4 & 3 & 2 & Echoing & V19 & 38 \\
\hline
\end{tabular}

3. If you listen to music, which elements can you hear? Please tick all the applicable answers.

Pleasant tones, but no melody

Only unpleasant sounds

Rhythm

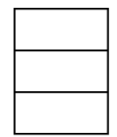

Melody

Lyrics

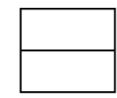

4. Can you distinguish between high and low notes?

YES

NO

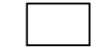

V25

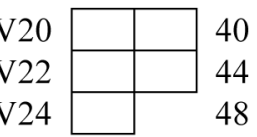

$\mathrm{V} 24$

44

5. Can you detect different musical instruments in a musical piece?

YES

NO

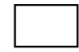

V26

6. Can you discriminate the lyrics (words) in a song?

YES

NO

V27

7. What did you find most annoying when you listened to music with the hearing aid?

V28

V29

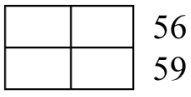

8. Please state any additional comments you may have regarding this subject. If you require the results of this study, please indicate it here.

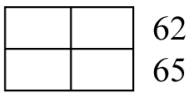

9. Do you require the results of this study?

YES

NO

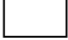

V32

68

PLEASE READ THROUGH THE QUESTIONNAIRE TO ENSURE THAT ALL THE
QUESTIONS WERE ANSWERED.

THANK YOU FOR YOUR CO-OPERATION 